\title{
Sociabilidades juvenis: notas etnográficas na periferia de Florianópolis-SC ${ }^{1}$
}

\author{
Youth sociabilities: ethnographic notes in the \\ outskirts of Florianópolis-SC
}

\section{Valdeci Reis*1}

Palavras-chave: Juventude;

Participação social; Etnografia; Hip hop.

Keywords: Youth;

Social participation; Ethnography; Hip hop.
Resumo: Estudo etnográfico desenvolvido no âmbito do doutoramento em Educação, cujo objetivo é analisar as sociabilidades de jovens integrantes do movimento hip-hop na capital do Estado de Santa Catarina. É na juventude que as sociabilidades se ampliam para além da família e da escola. Ao vivenciarem novas interações praticando Skate na praça do bairro, duelando freestyles nas Batalhas de Rap, discutindo suas poesias com outros internautas, via aplicativos digitais, os sujeitos observados nesta pesquisa constroem processos de resistência, denunciando a ausência de uma política pública efetiva para a juventude - que vá além das prescrições legislativas -, ou seja, que de fato se materialize em ações concretas nas suas vidas. Os dados etnográficos trazem à tona cenas de jovens oriundos das 'quebradas' da Ilha de Santa Catarina em processos criativos de afirmação que, através do ritmo e poesia, refletem sobre a sua condição juvenil na sociedade, os preconceitos que partem da população aos territórios periféricos da cidade, bem como a violência policial protagonizada pelo Estado.

Abstract: Ethnographic study developed as part of a doctoral research in education. It aims to analyze the sociability of young members of the hip hop movement in the capital of the State of Santa Catarina. In youth, sociability expands beyond the family and the school. By experiencing new interactions practicing Skate in the neighborhood square, dueling freestyles in the Battles of Rap, and discussing their poetry with other Internet users via digital applications, the young people observed in this research build resistance processes and denounce the absence of an effective public policy for youth - that goes beyond legislative prescriptions -, in other words, that actually materializes in concrete actions in their lives. The ethnographic data bring up

\footnotetext{
${ }^{1}$ Recebido em 10/02/2020. Aceito em 25/04/2020

$*^{1}$ Pedagogo, mestre em educação, doutor em educação pela Universidade do Estado de Santa Catarina (UFSC). E-mail: pedagovaldeci@gmail.com.
} 
scenes of young people from the periphery of Santa Catarina Island, in creative processes of affirmation that, through rhythm and poetry, reflect on their condition in society, the prejudices against communities living in the periphery, as well as the police violence carried out by the State.

\section{Introdução}

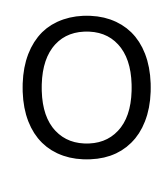

presente artigo é uma espécie de convite ao leitor para um passeio junto com MC Rever e seus amigos da Batalha de Rap da Central, uma reunião de jovens, em sua maioria rappers - que, ao longo das observações, foram identificados também adeptos do rock, reggae e punk -, que acontece toda terça-feira em uma praça pública, ao lado de um parque no bairro Campeche, Sul da Ilha de Santa Catarina.

Assim, antes de conduzir os leitores às quebradas do município de Florianópolis, é relevante ressaltar que, considerando a etnografia também uma forma de escrita, procuro, nestas notas, seguir as pistas dos antropólogos Raphael Bispo (2010) e Rosana Pinheiro-Machado (2016) no esforço de aproximação e distanciamento dos sujeitos observados, considerando que tal movimento pode fornecer alguns indicadores para compreensão dos fenômenos complexos que me proponho a refletir neste artigo.

Durante o trabalho de campo, tendo por base as teorizações da antropóloga Marisa Peirano (2014), procurei colocar em ação os três elementos básicos que fundamentam a etnografia: I) elucidação, contextualizando o lócus observado e seu entorno (comunidade); II) transformação de maneira clara, objetiva e fluída da situação vivida em texto escrito; III) análise das percepções do grupo observado, articulando a problemática de pesquisa e o referencial teórico do fenômeno pesquisado.

Em meio ao processo do fazer etnográfico, recorro aos protocolos: diário de campo e entrevista em profundidade (WEBER, 2009). É importante ressaltar que o diário não se trata do relatório de pesquisa a ser publicado em periódico científico, mas sim um conjunto de narrativas descritivas, muitas vezes contendo situações autobiográficas vivenciadas no campo de pesquisa. São informações preciosas que ajudarão o etnógrafo na análise das percepções do grupo observado, bem como na avaliação do percurso etnográfico realizado.

Ao acompanhar o percurso de jovens estudantes, MCs, dançarinos do break e produtores de rap, constatei que o movimento Hip hop da Ilha de Santa Catarina atua próximo de "uma rede de proteção social" que, além de contribuir para a autoestima dos participantes e para o aprendizado sobre técnicas de

Caderno Eletrônico de Ciências Sociais, Vitória, v. 8, n. 1, pp. 9-30, 2020. 
produção musical, é responsável por um profícuo debate sobre o cenário político atual, explicitando as contradições da sociedade brasileira.

Não se paga para participar do evento cultural, que é aberto a todos. Os ônibus - linhas interbairros - vindos de áreas distantes - Caieira da Barra do Sul, Tapera, Armação, Lagoa da Conceição, Rio Vermelho - levam os jovens ao Parque Pacuca e, com eles, muito movimento e burburinho. A reunião também atrai os jovens moradores das comunidades próximas: Areias, Rio Tavares, Ribeirão da Ilha, Porto da Lagoa. As roupas largas, com seus acessórios, bem como tênis de cano alto, contrastam com os trajes fitness vestidos pelos moradores do bairro Campeche, que também circulam pela área para a prática desportiva.

As reflexões tecidas neste artigo têm por base dados de uma etnografia urbana realizada ao longo do ano de 2019 no âmbito do processo de doutoramento em Educação. As cenas escolhidas para discussão são as Batalhas de Rap, que serão examinadas nas próximas seções como um produto da sociabilidade ${ }^{2}$ juvenil, ou seja, uma forma peculiar de como os jovens pobres e da 'quebrada' se apropriam do espaço urbano da cidade neoliberal ${ }^{3}$, por meio de processos de socialização vivenciados na praça pública e nos aplicativos digitais, conseguem formar uma ação coletiva, mobilizando internautas e jovens moradores de áreas em situação de vulnerabilidade social em torno de uma identidade comum.

\section{Nas quebradas da Ilha de Santa Catarina...}

O relógio marcava 14:30 quando meu smartphone tocou, alertando que um novo recado chegara no aplicativo de conversas. Sob meus olhos saltava a imagem de um palco montado, em que aconteceria a Batalha de Rap, seguida das informações sobre a reunião cultural juvenil. Rever, um dos Mestres de Cerimônia da Batalha de Rap da Central, jovem que vinha conversando nas últimas duas semanas via redes sociais, confirmava que o evento de rap aconteceria naquela noite.

\footnotetext{
${ }^{2}$ Neste trabalho, o conceito de sociabilidade é refletido à luz das teorizações do sociólogo Georg Simmel (2006).

3 O conceito de cidade neoliberal tem por base as teorizações de Joe Painter (2010) e Rodrigo José Firmino (2018). Tais autores possuem vasta publicação que problematiza a atuação empresarial na apropriação de espaços públicos - ruas, praças, parques - em cidades da América Latina. Esses conglomerados atuam como cooperadores - junto com governos e organizações não governamentais -, delimitando como os cidadãos podem usufruir do ambiente que deveria ser de acesso a todos. Especificamente na cidade de Florianópolis, constata-se uma tentativa de sucessivos governos - nas últimas duas décadas - em 'aburguesar' determinadas áreas, na tentativa de invisibilizar patrimônios históricos culturais, bem como territórios que foram palcos de lutas comunitárias históricas na capital de Santa Catarina.
}

Caderno Eletrônico de Ciências Sociais, Vitória, v. 8, n. 1, pp. 9-30, 2020. 
Combinamos de nos encontrar no local em que ocorreria o evento, uma praça no bairro Campeche, em frente ao Parque Pacuca, muito utilizado para a prática de esportes e exercício físico. Próximos do local existem alguns bares e lanchonetes, um estacionamento, além do Posto de Saúde do bairro.

Por volta de 19:00, cerca de 120 jovens - a maioria entre 14 e 18 anos circulavam em pequenos grupos pela praça. Rever estava atrasado. Sentado em um banco de madeira, virei assunto em algumas rodas, onde integrantes falavam alto e se movimentavam sem parar de um lado para outro: "o que aquele 'mano' estranho está fazendo ali?" - indagou um adolescente. "Será que ele vai 'colar' na batalha? Mas ele não tem cara de Rapper". Outro moço comentou que o movimento despertou o interesse do 'asfalto', ou seja, tem sido comum os 'playboys' aparecerem nas Batalhas de Rap, mas estes não têm compromisso algum com o movimento Hip hop, estão ali apenas pela 'zoeira' e 'pegação' e isso tem causado muitos problemas para os organizadores MCs.

A situação ficou mais tranquila com a chegada de L'Marx, jovem conhecido da cena Hip hop de Florianópolis, que havia sido um dos meus principais informantes em outro estudo etnográfico realizado ${ }^{4}$. $\mathrm{O}$ abraço do MC - seguido pelo comentário "vejam só quem resolveu voltar à 'quebrada', o misterioso detetive da universidade" - representou simbolicamente algo próximo de um carimbo no passaporte do etnógrafo, que ainda buscava alternativas para se movimentar naquele território culturalmente estrangeiro para o pesquisador. A cena protagonizada pelo Rapper era acompanhada atentamente por parte dos jovens curiosos em desvendar o 'ser estranho' que havia se materializado, inesperadamente, na praça.

Fui apresentado para algumas pessoas próximas. Enquanto aguardava a chegada de Rever, conversei com Mano Intruso, jovem que vem participando do movimento há seis meses. A forma como Mano chegou às batalhas é no mínimo curiosa. Relatou-me que participa da Igreja Universal do Reino de Deus - um dos elementos decisivos para o ingresso na religião foram os cantos, bem como os louvores muito comuns nos cultos ecumênicos da igreja neopentecostal.

O jovem avançou em sua narrativa, afirmando que a instituição religiosa tem uma forma muito peculiar de expandir sua ramificação de atuação. Por exemplo, existe uma ponte na cidade - Barra da Lagoa - que, nos últimos meses, vem sendo palco de muitos suicídios. Então, os "discípulos de Jesus" se revezam em escala próximos ao local. Caso uma pessoa resolva tentar o ato, o 'enviado' entra em ação, conversa com a pessoa, tenta entender o que está

\footnotetext{
4 Estudante secundarista quando desencadeou a onda de ocupações de escolas e universidades em 2016, foi um dos líderes das ocupações escolares ocorridas em Florianópolis durante o ano de 2016.
}

Caderno Eletrônico de Ciências Sociais, Vitória, v. 8, n. 1, pp. 9-30, 2020. 
acontecendo, acolhe e oferece a igreja como uma alternativa para superar o momento difícil.

Foi desta forma que Intruso chegou à Batalha da Central. O pastor de sua igreja acreditava que era preciso resgatar aqueles jovens que estavam perdidos para o 'Capeta'. Sendo assim, escalou Intruso para monitorar a área e verificar jovens em potencial para conversão. Todavia, algo inusitado, fora do 'script ecumênico', ocorreu. A batida, as rimas e as poesias declamadas atraíram o interesse de Intruso, que passou a gostar do ritmo. É preciso ressaltar que foi a música que atraiu o jovem para a igreja.

Mano Intruso vive um dilema: gosta de rap, mas também dos louvores declamados no púlpito de sua igreja. Revelou este dilema para sua mãe que, desde então, vive em pânico, insiste de forma enfática em levá-lo na 'sessão de descarrego'. Ao longo das minhas conversas com o jovem, que se tornou algo rotineiro todas as terças-feiras, este me revelaria ainda outra situação: é homossexual. Questionado sobre como essa situação era tratada na igreja, afirmou que "a ordem é acolher a todos, Jesus nunca condenou ninguém por sua opção sexual". Mas é outro trecho da fala do jovem que despertou minha atenção: afirmou que, via redes sociais, tem conversado com jovens evangélicos de várias regiões do país, simpáticos à causa da diversidade. Eles estão discutindo a possibilidade de fundar o coletivo 'juventude universal pela diversidade'.

Existem três elementos indispensáveis que constituem o sujeito 'Mano Intruso': é evangélico, rapper e gay. E não está no horizonte deste jovem abrir mão de uma dessas características. Sobre o lado mais tenso destas sociabilidades - vivenciadas na igreja -, o jovem demonstrou disposição para se aliar a outros jovens evangélicos e tentar impulsionar uma nova dinâmica na instituição religiosa.

Tais mudanças já não causam grande estranheza para os jovens desta geração. Vivendo em um momento histórico em que o presencial e o virtual se imbricam constituindo-se uma mesma realidade, convivendo com famílias multirreligiosas, os jovens de hoje se movem com mais familiaridade em um jogo menos previsível de percursos e combinações, bem como ampliam o repertório de trajetórias religiosas possíveis. (NOVAES, 2018, p. 353).

Obviamente que todas essas interações sociais vivenciadas por Mano Intruso são atravessadas por dilemas e tensões. Alguns integrantes do movimento Hip hop demonstram perplexidade diante de um Rapper evangélico na Batalha, tendo em vista que uma das funções do rap é exatamente questionar, desestabilizar o que está naturalizado pela sociedade. Esta é a posição de Kaká, ressaltou o jovem em conversa reservada comigo. Para ele, se

Caderno Eletrônico de Ciências Sociais, Vitória, v. 8, n. 1, pp. 9-30, 2020. 
na década passada, os meios de comunicação de massa eram a grande fonte de alienação da sociedade, atualmente as igrejas evangélicas ocuparam tal posto, especialmente nas 'quebradas'.

Neste artigo, recorro também às análises da antropóloga Regina Novaes (2006) para afirmar que as categorias morros, quebradas e periferia que irão surgir nas narrativas dos jovens observados não são utilizadas no sentido estrito geográfico, mas como categorias construídas socialmente. Sobretudo no movimento Hip hop, os jovens se apropriaram destes conceitos surgidos inicialmente nas comunidades em situação de vulnerabilidade social e risco: periferia (São Paulo), favela (Rio de Janeiro), morro (Porto Alegre).

Diante do exposto, a partir das análises das narrativas e observações realizadas com os jovens em Florianópolis, é possível afirmar que a categoria 'quebrada' diz respeito a uma construção social para se referir às áreas aonde os serviços públicos chegam de forma precária. Todavia, esses sujeitos não utilizam a palavra como um estigma. O movimento cultural tenta atrelar novos significados políticos ao termo e também tenta exaltar a cultura efervescente que emerge nestes territórios.

O Rap (com seus DJs e MCs), o break e o grafite compõem a trilogia de um fenômeno social que é chamado, pelos próprios participantes, de movimento, ou cultura hip hop. O hip hop não é um movimento orgânico que produz grupos homogêneos. Ao contrário, existem várias correntes, linhas e ênfases que diferenciam o rap feito em países, cidades, bairros e grupos específicos. A circulação de bens culturais, como se sabe, não se faz nunca em uma direção unilateral. Cada manifestação de rap é um resultado singular do encontro de elementos da cultura local com informações globais. (NOVAES, 2006, p. 116).

MC Maná (17 anos), uma das organizadoras do evento que ocorre todas as terças-feiras, me explicou que as Batalhas de Rap incluíram o quinto pilar conhecimento - que, ao lado do Mestre de Cerimônia, do DJ, do break (dança de rua) e do grafite, compõe o movimento Hip hop de Florianópolis.

Conforme o horário avançava, o número de jovens aumentava e chegavam também algumas pessoas não tão jovens, o que Maná classifica como "a velha guarda do Rap de Floripa". Rever não chegara. A jovem avisoume que teria que conduzir a batalha naquela noite.

\section{A efervescência política e cultural das Batalhas de Rap}

Caderno Eletrônico de Ciências Sociais, Vitória, v. 8, n. 1, pp. 9-30, 2020. 
Dani Black, um dos jovens que acompanhei na escola durante o percurso etnográfico realizado em $2018^{5}$, que, naquela noite, aguardava ansiosamente o início do evento, me explicou que as batalhas têm como prelúdio os duelos [jogos] de rimas que aconteciam nos guetos. Enquanto aguardava na fila do SINE ${ }^{6}$, "a galera colava na rima improvisada, [fazendo] uma reflexão sobre o drama vivido diariamente".

Sobre o formato atual que acontece nos espaços públicos de Florianópolis, o adolescente me informou que o evento nasceu pela resistência, uma forma de protesto diante da inexistência de cultura aberta [pública] para a juventude na cidade. Neste sentido, Dani Black vê as batalhas como o principal difusor cultural para juventude pobre: "as poesias e as rimas passam muito pela contestação política e o descaso com o povo da quebrada, sabe!".

Com a ausência de Rever, Maná tomou a liderança da organização e fez a lista dos MCs dispostos ao confronto de rimas naquela noite. As Batalhas de Rap são divididas em três grandes momentos: batalha de conhecimento, momento de declamação de poesias e batalha de sangue. Entre a sequência de duelos, também é comum 'rolar' alguma apresentação de beatbox ${ }^{7}$, freestyle ${ }^{8}$ ou break ${ }^{9}$.

Nas batalhas de conhecimento, os temas são escolhidos pelo público presente. Aprovada a temática que deve conduzir o jogo de rimas, os dois MCs têm 40 segundos para preparar seus versos. Dani explicou que um MC precisa pensar em muitas linhas de fuga. Revelou-me também que, em casa, ele esquematiza um tema em sua mente. Na sequência, ensaia várias possibilidades de improviso em frente ao espelho. Às vezes treina com seus amigos internautas, fazendo uma espécie de aquecimento pelo Skype. Só depois ele encara a batalha em praça pública. Ao ser questionado se iria enfrentar o duelo aquela noite, disparou: "Mano, cantar rap nunca foi pra homem fraco. Saber a hora é pra homem sábio". Por meio de um trecho da música 'Sucrilhos', do Rapper paulista Criolo, o jovem me revelara que estava ali só para observar.

\footnotetext{
${ }^{5} \mathrm{O}$ percurso etnográfico realizado durante o doutoramento em Educação é dividido em duas etapas: durante o ano letivo de 2018 acompanhei uma turma de nono ano de Ensino Fundamental. No ano de 2019 continuei interagindo com esses jovens nas Batalhas de Rap. ${ }_{7}^{6}$ Agência do Sistema Nacional de Empregos.

7 Termo da cultura do Rap e do Hip Hop, trata-se de uma performance artística de reproduzir sons de bateria com a voz, boca e nariz (CARMO, 2003).

${ }^{8}$ Subgênero do Rap (REIS, 2020).

${ }^{9}$ Dança de rua, uma das expressões da cultura Hip Hop (REIS, 2020). Embora em algumas regiões do país como, por exemplo, nos Estados do Sudeste, exista uma profícua discussão na literatura sociológica no que se refere à utilização ou não da expressão "break". Neste trabalho, mantemos tal denominação, considerando que, no sul do país, esta é a forma como os integrantes do movimento hip-hop denominam tal expressão cultural.
}

Caderno Eletrônico de Ciências Sociais, Vitória, v. 8, n. 1, pp. 9-30, 2020. 
O confronto entre dois MCs participantes ocorre em uma sequência de três rounds de 30 segundos. Após o confronto de versos e rimas, o público presente escolhe o participante que desenvolveu melhor a ideia e fez a melhor performance. Dependendo do número de inscritos, pode haver oitavas, quartas e semifinal antes do grande ápice da noite - o confronto final.

Nas batalhas de sangue o tema é livre, um MC inicia a declamação das estrofes, que pode ser acompanhada por um DJ ou sequência de beatbox. 0 oponente precisa responder ou dar continuidade ao conteúdo abordado pelo colega que iniciou o duelo. Muitas vezes, na tentativa de chocar ou denunciar a opressão que o povo negro vive nas 'quebradas', palavrões entram nas estrofes, o que é proibido nas batalhas de conhecimento.

O rap cultiva uma sensibilidade justiceira, ao denunciar situações de injustiça, para anunciar outros futuros. As palavras soletradas são recuperadas de uma semiótica de rua, transgressiva por natureza, palavras encavalitadas em palavrões para melhor insultar, atingir, provocar. Palavras que são voz de consciência, que se vestem de queixumes, que se revestem de revolta. Voz singular (a de vocalista) que contagia, que se transforma num coletivo (nós, os do movimento) que se insurge contra eles (que não nos entendem). (PAIS, 2006, p. 13).

"Ser Rapper é uma responsabilidade social", sendo que o movimento é a voz da periferia. Por meio do ritmo e poesia, o cantor/compositor transmite as suas vivências. A partir desta definição, Kaká considera inusitado o interesse dos 'playboys do asfalto' em aderir ao movimento. "Qual é a vivência que esses caras têm? Dormir todas as noites na sua confortável cama box?". Para o MC, há diferenças significativas entre o jovem preto que mora nas quebradas e 0 jovem branco de classe média que mora no asfalto, pois este não é perseguido pela polícia por conta da sua cor, ou pela localização do seu domicílio.

"Mano, eu sou um ser político quando eu acordo e percebo que ainda estou vivo nesta cidade, saca? Onde a polícia tem permissão para caçar e exterminar o preto. Quando eu chego na praia, 'bixu' [irmão], eu sou um ser político". Neste sentido, Kaká acredita que a batalha é um importante espaço de reflexão e formação política; é também um ambiente de sociabilização que consegue reunir os jovens das quebradas, a pessoa em situação de rua, o estudante de classe média e também o playboy branco, "afinal, não há como delimitar quem pode participar das batalhas, sacou?".

Acredita que, mesmo que a sociedade permaneça calada diante das atrocidades colocadas em curso pelo atual governo [federal], consegue vislumbrar uma revolução silenciosa em movimento que está ganhando fôlego. "Semana passada deram 80 tiros no carro do músico lá no Rio [Evaldo Rosa. Na

Caderno Eletrônico de Ciências Sociais, Vitória, v. 8, n. 1, pp. 9-30, 2020. 
ação protagonizada pelo Exército, o catador de recicláveis, Luciano Macedo, também morreu]. Ontem [a Polícia Militar] matou dois [jovens] na Costeira"10. Embora não consiga enxergar quais vivências o 'playboy branco' poderia transformar em letra de Rap, avalia como positivas as diferentes tribos que circulam pelas Batalhas. Afirma que mesmo o jovem morador do metro quadrado mais caro de Florianópolis não tem perspectiva de emprego, de universidade pública, já que o atual governo declarou guerra ao conhecimento e à ciência. Ressalta ainda que o jovem, independentemente da classe, está condenado a um futuro de incertezas. Para Kaká, direitos como habitação e aposentadoria serão lembranças de um passado nostálgico: "a hora que todos tiverem clareza da sua condição precária nessa sociedade, o levante popular entrará em ação, 'bixu', e o Rap dará a tônica da revolução".

\section{"O Hip hop é isso, é empoderamento, é atitude!"}

A hora estava bastante avançada - passava das 23:00 - quando Rever chegou à praça. O perfil de quem circulava no local tinha alterado significativamente desde que eu chegara ao local. Os adolescentes menores de idade tinham retornado quase todos às suas residências, enquanto outros jovens "de diferentes tribos" surgiam, muitos carregando garrafas de bebidas alcoólicas. A Batalha de Rap saía de cena para dar lugar a algo que pode ser descrito como uma grande discoteca a céu aberto.

Rever me cumprimentou e se desculpou pelo furo. Com os olhos cheios de lágrimas, informou-me que passara por um imprevisto atípico em casa; sua mãe sofrera um acidente de trabalho. Percebi que ele não queria dar detalhes do acontecido, mas informou ainda que só aparecera porque havia combinado antecipadamente comigo.

Ao observar um grande número de jovens - com mais de 18 anos circulando no local, bebendo e compartilhando bebida alcoólica, desabafou: "tem muita gente que está aqui pela zoeira e curtição, não tem compromisso algum com as causas do movimento". Explicou-me que o rap entrou na sua vida quando ainda era criança, aos 11 anos de idade [hoje tem 20]. Rever disse-me que entrou no movimento por meio do break (dança de rua), que considera uma porta de entrada para muito conhecimento e sabedoria.

A partir disso começou a ouvir rap, buscar os grupos nacionais e o primeiro que o impactou foi o Grupo Facção Central. Relembrou que, à época, a música "Eu Não Pedi Pra Nascer" [Facção Central] tocava em todos os cantos do seu bairro. Enquanto ouvia as estrofes, refletia sobre a similaridade da letra

${ }^{10}$ Comunidade erguida sob a encosta do bairro Carianos.

Caderno Eletrônico de Ciências Sociais, Vitória, v. 8, n. 1, pp. 9-30, 2020. 
com o que observava nas 'ruelas' da sua comunidade [Areias, Sul da Ilha]. Sentado ao meu lado, em um banco, tentou cantar parte da letra:

\section{Minha mão pequena bate no vidro do carro \\ no braço se destacam as queimaduras de cigarro \\ A chuva forte ensopa a camisa, o short \\ qualquer dia a pneumonia me faz tossir até a morte \\ Uma moeda, um passe me livram do inferno \\ me faz chegar em casa e não apanhar de fio de ferro.}

(DIÁRIO DE CAMPO - Batalha da Central, 09/04/2019).

Trago à tona a frase que escreveu no aplicativo de conversa em mensagem enviada ao meu celular no início da tarde. Rever afirma que, hoje em dia, as "pessoas têm um pensamento muito igual, saca? Muito maquinizado!". Acredita que o Hip hop instiga as pessoas a refletirem para além da bolha. "Então, o Hip hop é isso, é empoderamento, é atitude!"

Começou a frequentar as Batalhas de Rap quando estudava no centro da cidade, no Instituto Estadual de Educação de Santa Catarina, período em que iniciou a Batalha da Alfândega - primeiro movimento de rap na ilha. "Comecei a colar ali e fiquei fascinado". Rever contou-me que tenta colocar em suas letras tudo que sente e fez questão de ressaltar que "antes de MC, antes de Rapper, eu sou, acima de tudo, poeta!".

Questionei-o sobre a diferença entre MC e Rapper. Rever esclareceu que é a forma, bem como a atitude de como o cantor se apresenta: "o MC [Mestre de Cerimônia] é o agitador, apresentador do evento; já o Rapper se preocupa mais com as composições, mandar bem nas rimas". Ressaltou que todo MC pode ser Rapper, mas nem todo Rapper é MC: "o Mestre de Cerimônia é o organizador da parada, saca? Ele pode cantar, pode eventualmente compor, mas sua função principal é fazer o evento bombar".

Relembrou que, quando os jovens começaram a descer o Maciço do Morro da Cruz [conjunto de comunidades em situação de vulnerabilidade na região central da ilha] para ocupar o Largo da Alfândega, o MC surgiu na cena do Hip hop como "o mestre que regia o evento enquanto o DJ tocava o som". Rever também avaliou que, na contemporaneidade, existem muitos Rappers, mas poucos MCs: "são realmente poucos os que conseguem orquestrar na batida sincronizada, junto com o DJ".

Com relação ao preconceito que parte da sociedade tem em relação ao movimento, afirma que já presenciou diversas represálias protagonizadas pela PM: "Chegavam lá pedindo o alvará da prefeitura". Foi quando o movimento atentou para o Art. 50, inciso IX, da Constituição Federal: "é livre a expressão da atividade intelectual, artística, científica e de comunicação,

Caderno Eletrônico de Ciências Sociais, Vitória, v. 8, n. 1, pp. 9-30, 2020. 
independentemente de censura ou licença" (BRASIL, 1988). "Agora chegam lá [Batalha da Alfândega] reclamando que tem menor bebendo", acrescentou ele.

Cara, é um movimento cultural livre, de pessoas que se reúnem em uma praça, como é que eu vou falar para um jovem, você é menor de idade, você não pode beber, você não pode estar aqui? O problema de quem bebe não é nosso, é do Estado. Então eles colocam esses problemas nas nossas costas e geralmente quem é o organizador não aguenta muito tempo por conta da pressão, então acaba tento uma rotatividade muito grande dos MCs organizadores [sic]. (DIÁRIO DE CAMPO - Batalha da Central, 09/04/2019).

Rever relatou que, uma semana após a eleição de 2018, a Polícia Militar apareceu novamente na Batalha da Alfandega [evento que ocorre toda quintafeira] e "tinha uns caras que estavam bêbados e acabaram jogando garrafas de bebida nos policiais". Diante de tal panorama, Rever aponta dois problemas: "por um lado, tem um povo que cola e que não se conscientiza. Outra parte vem para batalha apenas por conta do 'auê', esquecendo dos elementos básicos que compõem a cultura Hip-hop".

Um debate que eu tenho procurado estabelecer é o seguinte, se você vem na batalha apenas pela diversão, tudo bem, mas fica tranquilo no seu canto, sacou? Não fica usando drogas ilícitas em público, por que a polícia pode vir por conta do seu cheiro. Às vezes tá passando um senhor por ali, e ele pode não gostar do cheiro. Então não cola, bebe em outro local, vai em outra praça! Situações como essa acabam com o movimento [sic]. (DIÁRIO DE CAMPO - Batalha da Central, 04/04/2019).

Enquanto caminhávamos para uma das lanchonetes próxima à praça, perguntei sobre o futuro. Afirmou que seu maior sonho é produzir um filme em escala nacional, que retrate a realidade do povo oprimido das 'quebradas', mas não imagina algo como "Cidade de Deus", produção cinematográfica que considera maquiada e distante da realidade. Sua inspiração é Glauber Rocha. A afirmação que acabara de ouvir me deixara estupefato [as alegorias do cineasta foram objeto de reflexão no quarto capítulo da minha tese de doutorado (REIS, 2020).

Levei ao debate Terra em Transe [clássico lançado em 1967]. O jovem relacionou muitos elementos do filme com a atualidade, sobretudo com o cenário político, bem como a polarização instaurada na sociedade entre direita e esquerda. Nas alegorias que pretende roteirizar para retratar as contradições da sociedade atual, acredita que os algoritmos poderiam substituir o Jornal de Júlio Fuentes [uma das críticas de Terra em Transe]. Ressaltou que é preciso muito estudo para entender as assimetrias de poder na contemporaneidade.

Caderno Eletrônico de Ciências Sociais, Vitória, v. 8, n. 1, pp. 9-30, 2020. 
Enquanto lanchávamos, relembrou uma situação vivenciada no ônibus duas semanas antes. Passando por uma das vias do centro da cidade, comentou com seu colega, que sentava ao lado, sobre uma roupa que vira na vitrine de uma loja. Ficaram discutindo o quanto era maneira, descolada. "Cara, quando eu cheguei em casa e acessei o Facebook, a publicidade daquela roupa estava lá".

Ao perceber meu interesse pela temática vigilância nas redes, revelou-me que é um dos organizadores da "CripTainha", um festival que vem sendo planejado e acontecerá na cidade, possivelmente no primeiro sábado de julho, inspirado nas "CriptoFestas". Trata-se de um evento que mistura cultura, discussão sobre os dilemas éticos da rede, bem como formação de "mídiaativistas" independentes.

As CriptoFestas surgiram inicialmente na Austrália em 2011 em protesto contra o autoritarismo do governo, que conseguiu aprovar no parlamento um projeto polêmico que colocou em xeque a privacidade dos internautas ${ }^{11}$. Isso se difundiu pelo mundo todo, no Brasil são eventos abertos e independentes onde a tecnologia é debatida como algo indissociável da política. Nas CriptoFestas debatemos política e fazemos tecnologia, e também fazemos tecnologia e debatemos política, tudo ao mesmo tempo, na prática. São temas comuns nestes eventos a proteção contra a vigilância, software e hardware livres, questões de gênero na tecnologia, mídia alternativa, formas holísticas de se pensar a nossa segurança, enfim... Com a Criptainha queremos construir um encontro aberto e divertido para a troca de experiências sobre estes assuntos. Nosso interesse é montar uma rede de resistência para os tempos difíceis que se aproximam [sic]. (DIÁRIO DE CAMPO - Batalha da Central, 04/04/2019).

Ao me mostrar a prévia da programação, o caráter acadêmico do evento foi o que mais me impressionou. Na programação havia palestras com objetivo de discutir as últimas publicações de Fernanda Bruno ${ }^{12}$ (UFRJ) e Shoshana Zuboff $^{13}$ (Harvard), mas também oficinas práticas de Mídia-Ativismo, defesa pessoal, técnicas de como reagir à truculência policial, além de rodas de capoeira e Hip hop. Rever, assim como outros jovens que venho acompanhando nas Batalhas de Rap, faz múltiplas coisas ao mesmo tempo: se envolve na causa de vários coletivos, faz vários 'bicos' para complementação da renda. A

\footnotetext{
${ }^{11}$ Uma excelente reflexão sobre os bastidores, bem como os desdobramentos da emenda constitucional que o governo australiano conseguiu aprovar no parlamento, é referenciada na série produzida pela Netflix intitulada 'Secret City'.

12 Livro Tecnopolíticas da Vigilância: Perspectivas da margem (BRUNO, 2018).

13 Artigo "Big Other: Capitalismo de vigilância e perspectivas para uma civilização de informação" (ZUBOFF, 2018).
}

Caderno Eletrônico de Ciências Sociais, Vitória, v. 8, n. 1, pp. 9-30, 2020. 
forma como se apresenta em sua página do Facebook nos fornece um panorama da relação que os jovens estabelecem com o mundo do trabalho na era da ubiquidade ${ }^{14}$. Na descrição, aparece: MC, improvisador, produtor audiovisual, fotógrafo, doodleartista, poeta, beatmaker, rapper e pichador. Está estudando para o vestibular, pretende ingressar no curso de Cinema da UFSC. É conhecido na cena Hip hop da cidade, consegue ganhar algum dinheiro com shows e eventos, mas precisa esporadicamente trabalhar como 'motoboy', entregando lanches, para complementar a renda.

Ainda sobre o cenário político no Brasil, comentou que, ao ouvir o relato de pessoas mais velhas de como era o país na década de 90 do século XX, acredita que a sociedade brasileira "está em marcha ré. As pessoas estão voltando a ter medo de andar à noite, as mulheres voltaram a se sentir inseguras, porque agora o playboy pode andar armado". Todavia, "o que mais assusta é a violência nas comunidades, protagonizada por policiais desde que o resultado das eleições presidenciais de 2018 foi proclamado".

Como já identificado em diversas pesquisas empíricas lideradas por Gilberto Velho (2006), a violência urbana é, na contemporaneidade, um dos maiores desafios às políticas públicas no Brasil. Sendo a Antropologia Urbana um campo de reflexão que sempre acompanhou as minorias despossuídas e dominadas em todos os sentidos - pobres, favelados, desviantes, pessoas em situação de rua -, torna-se interessante acompanhar como a juventude reage diante deste fenômeno complexo.

A vida nas grandes cidades vem sendo marcada por um assustador aumento da violência intra e interclasses. Sem dúvida, esse é um dos problemas mais graves que atingem a sociedade brasileira, associado à desigualdade e à dificuldade de comunicação e diálogo entre diferentes segmentos sociais. Trata-se de uma crise social cultural. Por isso mesmo é importante acompanhar situações e casos de interação social construtiva e pacífica, com todas as suas ambiguidades e contradições, para pensarmos nos rumos e nas perspectivas dessa sociedade. As juventudes, com sua heterogeneidade e dinamismo, com novos tipos de projetos e trajetórias, devem ser acompanhadas com cuidado e atenção. Essas combinações e sincretismos, de algum modo originais, certamente podem nos ajudar a pensar melhor sobre os problemas teóricos e concretos da vida social. (VELHO, 2006, pp. 199-200).

\footnotetext{
${ }^{14}$ Conceito desenvolvido pela pesquisadora Lúcia Santaella (2013) para analisar a condição humana contemporânea mediada por artefatos tecnológicos. Na ciência da comunicação, a ubiquidade é definida como a habilidade de comunicar a qualquer hora, em qualquer lugar, por meio de um artefato tecnológico conectado à internet.
}

Caderno Eletrônico de Ciências Sociais, Vitória, v. 8, n. 1, pp. 9-30, 2020. 
Estudo realizado pelos pesquisadores Humberto Soto e Daniela Trucco (2015) sobre a violência na América Latina aponta que os índices de violência na região superam os dos países do Oriente Médio que estão envolvidos em conflitos de guerra civil. Observa-se, nos países latinos, "una violencia extrema em la sociedad civil, al punto de convertirse en la zona con la mayor tasa de homicidios del mundo. La violencia es la principal causa de muerte entre los jóvenes" (2015, p. 116).

$\mathrm{Na}$ cidade de Florianópolis, de fato, desde o início de 2019, os meios de comunicação de massa têm repercutido intensamente as mortes decorridas das operações policiais nas 'quebradas' da área central do município, em especial nas comunidades: Morro da Mariquinha, Morro Da Queimada e MontSerrat. Diante da truculência instaurada nestas áreas, consideradas pelas autoridades como em situação de vulnerabilidade social e risco, as lideranças comunitárias colocaram em curso uma série de atos para denunciar o racismo institucional da Polícia Militar de Santa Catarina.

A morte de Vitor Henrique Xavier Silva Santos, jovem negro de 19 anos, sem antecedentes criminais - executado com cinco tiros dentro da sua casa pela PM em 18 de abril de 2019 -, inflamou ainda mais o debate que já vinha ocorrendo nestas regiões. Os moradores se mobilizaram e desceram o morro para uma grande "Marcha contra a violência policial, em defesa dos direitos e pela democracia", o primeiro de uma sequência de grandes atos que a cidade de Florianópolis vivenciou ao longo dos anos de 2019 e 2020.

\section{À guisa de conclusão: que os dados etnográficos evidenciam sobre a juventude na contemporaneidade?}

O percurso etnográfico desta pesquisa, ao sair da escola e acompanhar também as sociabilidades juvenis nos espaços urbanos da cidade de Florianópolis, traz elementos sociológicos mais amplos para debater a juventude em tempos conturbados, onde assistimos ao encolhimento do Estado na esfera pública, no Brasil e na América Latina, bem como à desregulamentação dos direitos sociais e à intensificação da exploração da classe trabalhadora em nível mundial.

Neste tópico, desenvolvo algumas considerações sobre a potência dos movimentos sociais contemporâneos, o quanto essa organização popular poderá se transformar em uma ferramenta poderosa para enfrentar o período obscurantista que estamos vivenciando em termos políticos no Brasil, entendendo por obscuro[a] a ação do Estado, "que destrói o indivíduo em nome da ordem, de uma comunidade de interesses ou até mesmo da razão" (TOURAINE, 2011, p. 192). Todavia, devo advertir aos leitores que, diante da intensificação do neoliberalismo pós-industrial, reestruturação produtiva do

Caderno Eletrônico de Ciências Sociais, Vitória, v. 8, n. 1, pp. 9-30, 2020. 
capital e hegemonia financeira, essa articulação gestada no âmbito dos coletivos juvenis e movimentos sociais organizados terá maior efetividade caso estas organizações tenham capacidade de colocar em curso processos de mobilizações mais amplos. Para isso, é preciso dialogar, bem como atuar conjuntamente com o movimento sindical e, em certa medida, com os partidos políticos progressistas para barrar retrocessos em curso no parlamento.

No âmbito acadêmico é consenso que os sindicatos estão completamente distantes de suas bases e os partidos políticos vivem uma profunda crise ética, especialmente no Brasil ${ }^{15}$. Qualquer alternativa para conter a devastação social em curso, porém, exigirá necessariamente articulação e diálogo desses três importantes pilares da sociedade - movimentos sociais, sindicatos, partidos. É preciso ressaltar que, quando advogo aproximação dessas três esferas, estou defendendo atuação conjunta e não que uma determinada organização seja cooptada por outra. Alain Touraine enfatiza que, na história da América Latina, é recorrente a tática dos governos extremistas de incorporarem as organizações populares nos aparelhos estatais ou na burocracia dos partidos. Para Touraine, "o caso clássico é o PRI mexicano, partido-Estado há meio século, que comanda diretamente os sindicatos operários e camponeses, assim como organizações urbanas" (1996, p. 135). O peronismo, na Argentina, é outro exemplo elucidativo, ao longo da história, pois em diversos momentos o partido cooptou centrais sindicais e movimentos sociais organizados para se manter no poder.

Uma pergunta emerge a partir da leitura das notas etnográficas estruturadas na seção anterior: é possível caracterizar o movimento Hip hop de Florianópolis como um movimento social organizado? Seguindo a teorização da socióloga Maria da Glória Gohn, retomo o conceito de movimento social:

Ações sociais coletivas de caráter sociopolítico e cultural que viabilizam formas distintas de a população se organizar e expressar suas demandas. Na ação concreta, essas formas adotam diferentes estratégias que variam da simples denúncia, passando pela pressão direta (mobilização, marchas, concentrações, passeatas, distúrbios à ordem constituída, atos de desobediência civil, negociações, etc.) até pressões indiretas. (GOHN, 2011, p. 335).

A partir de tal definição, fundamentada na perspectiva teórica de Touraine (1996) e Castells (2013), é possível afirmar que as Batalhas de Rap observadas no percurso etnográfico desta pesquisa vão muito além de uma simples articulação de jovens que se reúnem semanalmente para discutir um gênero musical. Há uma pauta política clara e objetiva, que é discutida diariamente nos grupos que emergem nas redes sociais digitais, no encontro semanal em praça pública, bem como nos versos declamados por meio do ritmo e poesia.

${ }^{15}$ Conferir análise de Ricardo Antunes (2018) e Sabrina Fernandes (2019).

Caderno Eletrônico de Ciências Sociais, Vitória, v. 8, n. 1, pp. 9-30, 2020. 
Ao longo da pesquisa, observei várias reuniões onde rappers, MCs e líderes do movimento estudantil organizado discutiam estratégias de mobilização contra os cortes anunciados pelo Ministério da Educação. Presenciei também uma articulação intensa junto às associações de bairro e aos conselhos comunitários, para construir conjuntamente táticas de enfrentamento à violência policial intensificada nos territórios periféricos.

Todavia, existem dentro do Hip hop dissensos e contradições. Há quem defenda que o movimento deveria se preocupar especificamente com produção musical e deixar as questões políticas para os políticos de carreira. Essa posição minoritária de alguns jovens tem provocado divisões e muita discussão. Para além desses dilemas, comuns em qualquer grupo social, a maior relevância das Batalhas de Rap está na capacidade de os participantes diagnosticarem a realidade social das 'quebradas', denúncia trazida à tona por meio do ritmo e da poesia.

Diante de tal contexto, é possível afirmar que o movimento Hip hop observado nesta pesquisa se aproxima do que Gohn (2011) classifica como novos movimentos sociais autônomos contemporâneos. "Atuando em redes, constroem ações coletivas que agem como resistência à exclusão e lutam pela inclusão social" (p. 336).

Ao longo das inúmeras conversas que tive com os participantes das Batalhas de Rap na Ilha de Santa Catarina, a palavra 'revolução' foi recorrente. Esclareço aos leitores que o termo utilizado com frequência nas narrativas juvenis é mais metafórico do que sociológico. Não estão no horizonte imaginário dos jovens observados ações que reivindiquem uma mudança brusca na estrutura econômica e política do Estado brasileiro. Os rappers não buscam um Estado comunista totalitário. A maioria desses jovens jamais ouviu falar em Karl Marx. Em tempos de teorias conspiratórias, devaneios propagados nas redes sociais e um suposto 'marxismo cultural', é importante que fique claro que o uso da expressão 'revolução', em sua maioria, foi empregado nas crônicas, versos e narrativas de forma irônica e/ou sarcástica. As 'linhas de fuga' registradas na seção anterior - apontam para a tentativa de construção de uma sociedade menos excludente, que respeite as mulheres, os LGBTS, os negros, bem como a liberdade religiosa. Esta é revolução que almejam, que alcance uma sociedade mais inclusiva e respeitosa. Ou, como sintetizou Kaká em uma das conversas informais que teve comigo, "que o povo da quebrada tenha a possibilidade de acessar os direitos garantidos na Constituição, mas historicamente negados a nós".

Etimologicamente, do latim, revolução pode significar: ato de revolver, giro, passagem sucessiva (de um corpo a outro), rolar para trás, enrolar. Mas revolução pode também estar associada à

Caderno Eletrônico de Ciências Sociais, Vitória, v. 8, n. 1, pp. 9-30, 2020. 
transformação que, no caso do rap, aconteceria pela intenção de informar, de comunicar o que sente e o que vive no cotidiano da periferia, para inverter o olhar do senso comum para aquela realidade social ou para colocar os sujeitos que vivem a situação de opressão, preconceito e discriminação diante do espelho. Os sentidos de revolver e de passagem sucessiva, combinados com o sentido de transformação, podem traduzir as intenções das palavras comunicadas no rap e, de modo reflexivo, provocar o giro e rolar para trás, através do reflexo que se projeta ao se olhar no espelho. (ESTECANELA, 2010, p. 284).

Alain Touraine afirma que "um movimento social é sempre um protesto moral; coloca-se por cima da sociedade para julgá-la ou transformá-la, e não no centro para manejá-la e orientá-la no sentido que exige a razão ou a história" (1997, p. 79). As narrativas dos jovens que frequentam a Batalha da Central convergem, em sua maioria, para um discurso igualitário, republicano, algo que se aproxima de uma utopia libertária e antiautoritária. Propostas extremistas, sejam à direita ou à esquerda, são completamente refutadas pelos jovens observados nesta pesquisa.

É este enfrentamento entre os determinismos e os poderes sociais, de um lado, e, de outro, a reivindicação dos direitos e do direito de ter direitos que a sociologia deve considerar como sendo o objeto central de suas análises e de suas observações. As lutas conduzidas pelos movimentos de libertação de todas as ordens tornaram possível essa inversão do pensamento social. Mas, no passado, é geralmente uma evolução inversa que se produziu, transformando os movimentos de libertação em poderes autoritários. Pois, se as dominações jamais são completas, ou totais, elas também nunca deixaram de existir. As ciências sociais não podem contentar-se em criticar os sistemas autoritários e todas as formas de dominação. Elas devem igualmente convencer que jamais um ator é reduzido à impotência e à falsa consciência, e que em toda a parte existem vozes que falam de ações possíveis. (TOURAINE, 2011, p. 193).

Direito ao emprego (com proteção social), à universidade, à cultura é o que impulsiona o movimento Hip hop da Ilha. Os jovens que dele fazem parte reivindicam também o direito à dignidade enquanto pessoa humana. Mesmo morando em um barraco na 'quebrada', gritam para que as autoridades os respeitem como cidadãos.

Nos últimos encontros que tive com os jovens interlocutores desta pesquisa, em 2019, fui informado das grandes mudanças que aconteceriam nos meses seguintes. Muitos conseguiram acessar o banco universitário. Mc Rever alcançou a primeira etapa do seu grande sonho: passou no vestibular para o curso de Cinema da Universidade Federal de Santa Catarina. Na última

Caderno Eletrônico de Ciências Sociais, Vitória, v. 8, n. 1, pp. 9-30, 2020. 
conversa que teve comigo, bastante emocionado e com os olhos lacrimejando, me revelou: "o governo do PT permitiu que o favelado pudesse chegar à universidade, mas não previu o quanto é difícil para o pobre da quebrada se manter neste espaço". Pela primeira vez, não sabia o que dizer para aquele jovem.

L'Marx se prepara para mudar para Foz do Iguaçu. Por meio do SISU, passou no processo de seleção da UNILA (Universidade Federal da Integração Latino-Americana), conquistou uma vaga na graduação em Letras - Artes e Mediação Cultural Latino-Americana. Está ansioso para conhecer o movimento Hip hop da tríplice fronteira, efervescência cultural consolidada no município paranaense que envolve jovens da Ciudad del Este (Paraguai) e Puerto Iguazú (Argentina).

Dudu também foi aprovado no vestibular da UFSC, ingressou no curso de Jornalismo. Como não consegue sobreviver com a renda dos shows que realiza, de segunda a sexta, no período da noite, trabalha como garçom em um restaurante no bairro Campeche. Considera sua rotina exaustiva, mas tem grande expectativa com o futuro.

Kaká se aproximou do Coletivo Vamos, uma corrente dentro do PSOL Partido Socialismo e Liberdade, que nasceu a partir das discussões promovidas pela Frente Povo Sem Medo, agremiação que congrega a pauta de vários movimentos sociais - LGBTQIA+, Negro, Ambientais, Indígenas, Sem Teto. Avalia a possibilidade de ocupar a política institucional, se candidatando a vereador nas eleições de 2020. Se analisarmos a geografia do voto das últimas eleições municipais de Florianópolis, os dados do Tribunal Regional Eleitoral TRE/SC - nos mostram que, em 2016, por exemplo, o candidato a prefeito pelo PSOL foi o mais votado nos bairros Lagoa da Conceição, Porto da Lagoa e na Comunidade das Areias (onde mora a maioria dos jovens sujeitos desta pesquisa). São dados reveladores, considerando que o então candidato destoava bastante dos políticos tradicionais. Trata-se de um acadêmico, professor de Urbanismo da Universidade Federal de Santa Catarina.

Com relação à votação para vereador em 2016, os dados do TRE/SC nos mostram que os três vereadores mais votados nos bairros citados são do PSOL. Dois desses parlamentares destoam completamente do que os jovens sujeitos desta pesquisa classificam como 'políticos de carreira'16. Uma análise da apuração dos votos das seções eleitorais da Comunidade das Areias nos revela que um candidato do PSOL, jovem e bastante articulado com os coletivos juvenis, foi o mais votado em todas as urnas. Em nível municipal, este

\footnotetext{
${ }^{16}$ Político que visita a periferia próximo ao período eleitoral promove alguma ação solidária e, depois, da eleição esquece a comunidade.
}

Caderno Eletrônico de Ciências Sociais, Vitória, v. 8, n. 1, pp. 9-30, 2020. 
candidato, que era estreante na política, consagrou-se como o segundo parlamentar mais votado no município.

É digno de registro que a região da planície do Campeche tem uma tradição histórica de mobilização. Na década de 80 do século $X X$, quando se intensificaram os movimentos migratórios na região da Grande Florianópolis pessoas do sudeste e nordeste que chegavam à cidade em busca de oportunidades -, os moradores do Campeche colocaram em curso um amplo debate sobre a ocupação da cidade, forçando a prefeitura municipal a iniciar a discussão sobre o plano diretor da cidade ${ }^{17}$. A partir desta intensa mobilização comunitária em defesa das questões ambientais, bem como de uma ocupação territorial organizada, a população local fundou veículos de imprensa comunitários - jornal impresso e rádio FM - para confrontar as narrativas da mídia comercial já existente na cidade. Decorridas três décadas, esses veículos ainda têm grande capilaridade na região, sendo referência no Estado de Santa Catarina no campo da mídia comunitária ${ }^{18}$.

A título de ilustração do quanto esta comunidade tem disposição para discutir a participação social comunitária, faço referência a uma reunião ordinária do Conselho de Saúde Local que havia incluído na pauta de discussões a 'violência policial nas quebradas'. Ao chegar na reunião, juntamente com os jovens da Batalha da Central, a primeira coisa que me impressionou foi o número de participantes: excluindo os jovens e os servidores do Posto de Saúde, contei 33 pessoas presentes. Em tempos de popularização do acesso à internet, onde parte dos internautas reduz a participação social, as 'discussões políticas de Facebook', a tradição de organização popular da região do Sul da Ilha constitui um elemento importante a ser ressaltado. Quando a Polícia Militar tentou acabar com a Batalha da Central por conta do barulho na praça depois das 22:00, a atuação do Conselho de Saúde e da Associação dos Moradores do Campeche foi essencial para sensibilizar os policiais e demonstrar que se tratava de uma reunião de jovens que discutiam e produziam arte a céu aberto.

Ainda sobre os interlocutores desta pesquisa com os quais mais interagi durante os dois anos de percurso etnográfico, Aninha, ao concluir o ensino fundamental na Escola Municipal do Ribeirão da Ilha, ingressou no Ensino Médio do Instituto Federal de Santa Catarina - IFSC. Acha a instituição muito diferente, mas está conseguindo ir adiante. Não foi reprovada em nenhuma matéria, mas teve dificuldades nas disciplinas de Cálculo e Geometria. A maior diferença que sente em relação à escola anterior é o método de avaliação, pois

\footnotetext{
${ }^{17}$ Leitores interessados na temática participação social na cidade de Florianópolis, conferir análise de Pereira $(2015 ; 2017)$.

18 Conferir documentário realizado pelos Jornalistas Elaine Tavares e Rubens Lopes que recupera a memória das lutas sociais travadas na década de 80 do século XX, bem como a criação das mídias alternativas no sul da Ilha de Santa Catarina (TAVARES; LOPES, 2019).
}

Caderno Eletrônico de Ciências Sociais, Vitória, v. 8, n. 1, pp. 9-30, 2020. 
considera a instituição federal mais criteriosa e que os professores cobram muito.

Kleber ingressou no Ensino Médio de uma Escola Estadual no bairro Rio Tavares. Sobre o futuro, almeja ingressar em curso técnico ou graduação tecnológica do IFSC. Não definiu a escolha, mas imagina algo próximo da área de edificações ou eletrônica. Também demonstra simpatia pelo campo da informática.

Dani Black ingressou no Instituto Estadual de Educação. Demonstra grande apreço pelo universo das artes. Uma das possibilidades que avalia após a conclusão do Ensino Médio é tentar o vestibular em música ou teatro na Universidade do Estado de Santa Catarina - UDESC -, mas ainda está analisando as múltiplas possibilidades. Sua grande meta para 2019 é 'passar de ano'.

\section{Referências}

ANTUNES, R. 2018. O privilégio da servidão: o novo proletariado de serviços na era digital. São Paulo: Boitempo.

BISPO, R. 2010. Heterotopiasemo: notas etnográficas sobre os desvios e inversões da juventude emocore no Rio de Janeiro. In: VELHO, G.; DUARTE, L. F. D. Juventude contemporânea: culturas, gostos e carreiras. Rio de Janeiro: 7 Letras.

BRASIL. 1988. Constituição da República Federativa do Brasil de 1988. Brasília: Senado Federal. Disponível em: http://www.planalto.gov.br/ccivil_03/constituicao/constituicao.htm . Acesso em: 06 dez. 2018.

BRUNO, F.; CARDOSO, B.; KANASHIRO, M.; GUILHON, L.; MELGAÇO, L. (Orgs.). 2018.Tecnopolíticas da Vigilância: perspectivas da margem. São Paulo: Boitempo.

CARMO, P. S. 2003. Culturas da rebeldia: a juventude em questão. São Paulo: SENAC.

CASTELlS, M. 2013. O poder da identidade. São Paulo: Paz e Terra.

FERNANDES, S. 2019. Sintomas Mórbidos: a encruzilhada da esquerda brasileira. Belo Horizonte: Autonomia Literária, 2019.

FIRMINO, R. J. Securitização, vigilância e territorialização em espaços públicos na cidade neoliberal. 2018. In: BRUNO, F; CARDOSO, B; KANASHIRO, M; GUILHON, L; MELGAÇO, L. (Orgs.). Tecnopolíticas da Vigilância: perspectivas da margem. São Paulo: Boitempo. 
GOHN, M. G. 2011. Movimentos sociais na contemporaneidade. Revista Brasileira de Educação, v. 16, n. 47, pp. 333-361.

NOVAES, R. 2006. Os jovens de hoje: contextos, diferenças e trajetórias. In: ALMEIDA, M. I. M.; EUGENIO, F. Culturas Jovens: Novos mapas do afeto. Rio de Janeiro: Zahar, pp. 105-122.

NOVAES, R. 2018. Juventude e religião, sinais do tempo experimentado. Intersecções, Rio de Janeiro, v. 20, n. 2, pp. 351-368.

PAINTER, J. 2010. Rethinking Territory. Antipode, v. 42, 2010, pp. 1.090-1118. Disponível em: <https://doi.org/10.1111/j.1467-8330.2010.00795>. Acesso em: 16.04.2020.

PAIS, José Machado. 2006. Buscas de si: expressividades e identidades juvenis. In: ALMEIDA, Maria Isabel Mendes de; EUGENIO, Fernanda. Culturas Jovens: Novos mapas do afeto. Rio de Janeiro: Zahar, p. 7-24.

PEIRANO, M. 2014. Etnografia não é método. Horizontes Antropológicos, v. 20, n. 42, pp. 377-391.

PEREIRA, E. M. 2017. Como anda a participação? As condições para a elaboração de planos diretores participativos. Revista Brasileira de Estudos Urbanos e Regionais, v. 19, n. 2, pp. 235-250. Disponível em: $<$ http://rbeur.anpur.org.br/rbeur/article/view/5380>. Acesso em: 02.03.2020.

PEREIRA, E. M. 2015. A alegoria da participação: planos diretores participativos pós-estatuto da cidade. Florianópolis: Insular.

PINHEIRO-MACHADO, R. 2016. Luzes antropológicas ao obscurantismo: uma agenda de pesquisa sobre o "Brasil profundo" em tempos de crise. Revista de @ntropologia da UFSCar, v. 8, n. 2, pp. 21-28.

REIS, V. 2020. Cenas Juvenis na escola, na cidade e nas redes: notas etnográficas na 'Ilha de Floriano' e tantos outros ilhéus. 2020. 234f. Tese (Doutorado) - Programa de Pós-Graduação em Educação, Centro de Ciências Humanas e da Educação, Universidade do Estado de Santa Catarina, Florianópolis.

SANTAELLA, L. 2013. Comunicação ubíqua: repercussões na cultura e na educação. São Paulo: Paulus.

SIMMEL, G. 2006. A sociabilidade. In: SIMMEL, G. Questões fundamentais de sociologia. Rio de Janeiro: Zahar, pp. 59-82.

SOTO, H.; TRUCCO, D. 2015. Inclusión y contextos de violencia. In: TRUCCO, D.; ULLMANN, H. Juventud: realidades y retos para un desarrollo con igualdad. Santiago: CEPAL, 2015. pp. 115-170.

Caderno Eletrônico de Ciências Sociais, Vitória, v. 8, n. 1, pp. 9-30, 2020. 
STECANELA, N. 2010. Jovens e cotidiano: trânsitos pelas culturas juvenis e pela escola da vida. Caxias do Sul: Educs.

TOURAINE, A. 1996. O que é a democracia? Petrópolis: Vozes.

TOURAINE, A. 1997. Podremos vivir juntos? Buenos Aires: Fondo de Cultura Económica.

TOURAINE, A. 2011. O mundo das mulheres. Petrópolis: Vozes.

VELHO, G. 2006. Juventudes, projetos e trajetórias na sociedade contemporâneas. In: ALMEIDA, M. I. M.; EUGENIO, F. Culturas Jovens: Novos mapas do afeto. Rio de Janeiro: Zahar. pp. 192-201.

ZUBOFF, S. 2018. Big Other: Capitalismo de vigilância e perspectivas para uma civilização de informação. In: BRUNO, F.; CARDOSO, B.; KANASHIRO, M.; GUILHON, L.; MELGAÇO, Lucas. Tecnopolíticas da Vigilância: perspectivas da margem. São Paulo: Boitempo.

WEBER, F. 2009. A entrevista, a pesquisa e o íntimo, ou por que censurar seu diário de campo? Horizontes Antropológicos, v. 15, n. 32, pp. 157-170.

\section{Filmografia}

20 anos de comunicação comunitária. Direção: Elaine Tavares, Rubens Lopes. Florianópolis, 2019, ARCCA. Disponível em: <https://www.youtube.com/watch?v=-YRCubvI3kc>. Acesso em: 12.11.2019.

Secret City. Direção: Emma Freeman. Austrália, 2018, Netflix. (primeira temporada)

TERRA em transe. Direção: Glauber Rocha. Brasil, 1967, DVD (1h 48min).

\section{Musicografia}

CRIOLO. Sucrilhos. São Paulo: Álbum Nó na orelha, 2014.

FACÇÃO CENTRAL. Eu não pedi para nascer. São Paulo: Álbum Direto do Campo de Extermínio, 2003. 